\title{
Weight change among repeat participants of an Aboriginal community-based weight loss program
}

Erika Bohn-Goldbaum ${ }^{1,2^{*}}$ D , Aaron Cashmore ${ }^{3,4}$, Rose Fonua ${ }^{5}$, Andrew Milat ${ }^{1,3}$, Kate Reid ${ }^{5}$, Leah Shepherd ${ }^{2}$, Adrian Bauman ${ }^{1,2}$ and Anne C. Grunseit ${ }^{1,2}$

\begin{abstract}
Background: Community-based weight loss programs may have potential to address overweight and obesity at the population level. However, participation patterns and individual outcomes from these programs are understudied. This study examined repeat participation patterns and participant weight change between contests over seven years of an Aboriginal Australian team-based program in order to identify (1) predictors of repeat participation and (2) associations with weight change between contests.

Methods: Data for the 12 contests from 2012 to 2018 were merged, with probabilistic record matching. A total of 7510 enrolments were registered for the 12 contests, representing 4438 unique people. Contest lengths varied from 10 to 16 weeks in duration. Non-repeat participants were those who only competed once in the program by the end of 2018, and repeaters were those who competed in at least two contests. Associations between repeat participation and participant baseline (i.e., first participation occasion) characteristics, change in diet and physical activity and percent change in weight during the first participation occasion were examined using crossed random effects (for person and team) regression adjusted for exposure to the program. Weight percentage change between contests was calculated for consecutive participation occasions occurring at least three months apart, converted to percent change per month. Weight change was regressed on number of repeat participation occasions adjusted for age, gender, baseline weight at first participation occasion, and weight percent change in the immediately preceding contest.
\end{abstract}

Results: One-third of the 4433 participants participated more than once, with women more likely than men to repeat. A $1 \%$ reduction in weight during a competition was associated with an increase in weight of $0.05 \%$ per month between competition end and subsequent participation. Regain was smaller the heavier participants were at their first participation.

Conclusions: While individuals benefit from weight loss through program participation, strengthening strategies for weight loss maintenance within or following the program could improve long-term weight outcomes and reduce weight cycling.

Keywords: Weight loss, Repeat participation, Aboriginal Australian

\footnotetext{
* Correspondence: Erika.Goldbaum@sydney.edu.au

${ }^{1}$ The Australian Prevention Partnership Centre, Sydney, New South Wales, Australia

${ }^{2}$ The University of Sydney, Sydney School of Public Health, Camperdown, New South Wales, Australia

Full list of author information is available at the end of the article
}

(c) The Author(s). 2020 Open Access This article is licensed under a Creative Commons Attribution 4.0 International License, which permits use, sharing, adaptation, distribution and reproduction in any medium or format, as long as you give appropriate credit to the original author(s) and the source, provide a link to the Creative Commons licence, and indicate if changes were made. The images or other third party material in this article are included in the article's Creative Commons licence, unless indicated otherwise in a credit line to the material. If material is not included in the article's Creative Commons licence and your intended use is not permitted by statutory regulation or exceeds the permitted use, you will need to obtain permission directly from the copyright holder. To view a copy of this licence, visit http://creativecommons.org/licenses/by/4.0/. The Creative Commons Public Domain Dedication waiver (http://creativecommons.org/publicdomain/zero/1.0/) applies to the data made available in this article, unless otherwise stated in a credit line to the data. 


\section{Introduction}

Weight loss interventions among Aboriginal Australians have proven effective in reducing weight and noncommunicable disease risk [1-5]. Effective interventions are particularly needed for a population of whom over two-thirds are overweight or obese and whose mortality rate is 1.6 times that of non-Indigenous Australians [6]. Community-based programs offer easy and affordable access and have potential to both strengthen community ties and improve physical health [7-9]. Outcomes from community-based weight loss programs can be difficult to establish due to the variety of program designs and reporting inconsistencies [10]; never-the-less, weight reduction and reduced risk of non-communicable disease have been demonstrated in other populations [11-14]. For Aboriginal Australians there is limited but positive evidence of effectiveness for community-based programs [15].

Losing excess weight has health benefits for cardiovascular and other risk factors [16] but the health effects from any weight regain are less clear, with some studies suggesting loss of health benefits attained through weight loss [17], increased health risks [18], or improved risks relative to those who remain at a stable weight [19] or maintain the lost weight [20]. Whilst there is a large literature documenting weight loss, there are far fewer studies examining maintenance of weight loss, with most finding poor maintenance rates and regain common [21, 22]. Additionally, little is known about weight maintenance among Aboriginal Australians.

Attendance in an intervention and in any postintervention program maintenance phase can aid weight loss and maintenance [23, 24]. Repeat program participation may also improve weight outcomes [11, 25, 26], particularly if the repetition is consecutive [27]. However, repeat participation may also indicate repeated loss/regain (weight cycling) if weight loss is not maintained in the interim, and weight cycling may be detrimental to health [28-32]. Thus, investigating characteristics of repeat participants and their weight changes in and between programs has potential public health implications.

Team-based weight-loss competitions are often used in wellness programming as they have wide reach for population impact [33]. There are some successful, repeated, team-based, community weight-loss competitions, but individual outcomes of community competitions are infrequently evaluated in peer-reviewed literature [33]. There are three notable exceptions based in the United States of America. Repeat participants in Shape Up Rhode Island, an annual 16-week state-wide team-based competition, were more likely to be older (> $40 \mathrm{yrs}$ ), obese and meet guidelines for attaining moderate physical activity (PA) and vegetable consumption compared to non-repeaters [27]. Completion rates and weight loss correlated with social influence [12, 14], and both more minutes/week in PA and more steps/day correlated to weight loss [14]. In the second study, employees in an annual 5-week team-based competition at a Michigan hospital lost weight, with their outcomes differing with participation patterns over the program's 5 years; over two-thirds of the employees gained weight between contests [34]. In the third study, individuals' weight changes within and between an annual 14-week community competition in Texas were documented [11]. Average weight loss among first-time participants who lost weight during their first participation was approximately $5 \%$ and lessened with each subsequent participation; weight regain between first and second participations was approximately $3 \%$, with nonconsecutive repeat participants experiencing more regain [11]. Factors associated with weight changes included gender, starting weight, and the number of repeat participations [11].

We recently evaluated a community-based team weight loss competition, the NSW Aboriginal Knockout Health Challenge (KHC) [15], a program open to Aboriginal Australians and Torres Strait Islander peoples aged 16 years or older. KHC contests have been held once each in 2012 and 2013, and twice per year since 2014 . Contest lengths have varied from 10 to 16 weeks in duration. The time between the start of the first (or only) contest in 1 year and the end of the previous contest ranged between 178 and 245 days, with shorter periods (17-94 days) between contests held in the same year. (Contests lengths and dates can be found in the additional file, supplemental Table 1). The program has been described in detail elsewhere [35]; briefly, teams of 20 or more persons compete to lose weight through PA and healthy eating. Participants may enrol as a member of a team at the beginning of any contest and teams selfdetermine their activities to support healthy lifestyle behaviours. The program capitalizes on Aboriginal Australians' values (e.g., community) and is structured for prize money to be directed to environmental and socioeconomic factors which disproportionally affect Aboriginal Australians and contribute to their poor health [6]. Our recent evaluation of the KHC found increased participation and significant average weight loss [15] but did not explore within-individual outcomes. Therefore, we analysed participation patterns, particularly repeat participation patterns, and participant weight change between contests over 7 years (2012-2018) of the KHC. The study aims were to identify (1) predictors of repeat attendance and (2) the effects of repeat attendance on weight change. Ethics approval for the secondary analysis was provided by the Aboriginal Health and Medical Research Council (Project 1125/15) and the University of Sydney (2019/425). 


\section{Methods}

\section{Data collection and treatment}

Participant outcomes are measured pre-post contest for prize allocation; written consent (provided by the participant, and, for those under 18 years of age, by their parent/legal guardian with the underage participant providing written assent) allows use of the data for prize calculation and research purposes. Participants join teams by submitting data and consent to a team manager; data are collated and sent to a central database. Data comprise name, date of birth and gender as well as objective measures of weight (to nearest $0.1 \mathrm{~kg}$ ) and height $(\mathrm{cm})$ which were collected by a health professional. From 2013, self-reported current smoking status, fruit and vegetable intake (servings of each on a typical day), and from 2014, PA (frequency in last 7 days of 20 min or more vigorous PA, $30 \mathrm{~min}$ or more of walking, and 30 min or more of moderate PA) were also recorded using validated questions [36]. At the conclusion of the contest, participants' weights are recorded by a health professional and self-reported lifestyle risk factors are reported via questionnaire using the same questions as at registration.

Data for the 12 contests were merged, with probabilistic record matching by participant name, sex and date of birth through an independent data linkage agency (The Centre for Health Record Linkage - http://www.cherel. org.au/; $0.05 \%$ false positive rate). The start and end dates of the 12 contests were then merged with the contest data.

\section{Participants}

A total of 7510 enrolments were registered for the 12 contests from 2012 to 2018, representing 4438 unique people. Six records ( $n=5$ people) were excluded because the participant was aged younger than 18 years and did not have parental consent for their data to be used, leaving 4433 unique people with 7504 enrolments.

\section{Primary outcomes}

This study had two primary outcomes: to identify (1) predictors of repeat participation and (2) associations with weight change between contests. Non-repeat participants were those who only competed once in the $\mathrm{KHC}$ by the end of 2018, and repeaters were those who competed in at least two contests. In order to account for the changing probability of repeating across time (because those whose first participation is later in the $\mathrm{KHC}$ series have less opportunity to repeat than those who start earlier [37]) an exposure variable was calculated as the number of contests between first and second occasion of participation or, for non-repeaters, the number of contests from first participation through to the 12th contest. Weight percentage change between contests was calculated for consecutive participation occasions which occurred a minimum of 3 months apart (i.e., between one contest's end and start of the next contest the individual competed in). The end weight of the previous contest was subtracted from the start weight of the next and the difference divided by the end weight of the previous. For example, a participant weighing $100 \mathrm{~kg}$ at the start of contest 7 and $95 \mathrm{~kg}$ at the end of contest $6(\sim 7$ months prior), would have a change of $5.3 \%$; a positive number therefore demonstrates a weight gain between contests. This was converted to a rate per month by dividing by the number of months between the two contests using the contest start and end dates.

\section{Data analysis}

Participation patterns were ranked from most to least common among the 4433 unique participants.

Further exclusions of the 4433 participants occurred at analysis. Two records were excluded from analyses as their weight change exceeded limits (e.g., a weight reduction greater than 30\%) used previously in a weight management program of a similar duration as the $\mathrm{KHC}$ [23]. All other weights were within limits (leaving 4432 people with 7502 records). For likelihood of repeat participation, data comprised individuals who had formed teams of $\geq 20$ persons at their first participation occasion (leaving 4312 people) and those whose first participation was prior to contest $12(n=4104$ people). For analysis on weight changes between competitions, analysis was limited to participants who had 2 or more participation occasions (leaving 1532 people with 3071 records) and to those occasions where contest participation had a minimum three-month gap (leaving 1132 people with 1794 records). Further, a complete case approach was used for all analyses (i.e., relevant records with missing data were excluded).

The associations between repeat participation and participant baseline (defined as first participation occasion) characteristics, change in diet and PA, and percent change in weight during the first participation occasion were assessed using bivariate analyses. Baseline characteristics included gender (male, female), age (years), weight $(\mathrm{kg})$, fruit and vegetable intake (per serve), and minutes of vigorous and moderate PA and walking. Fruit and vegetable intake were also categorised dichotomously as meeting (or not meeting) current dietary recommended levels of two serves of fruit and five serves of vegetables [38]. PA was categorised dichotomously as having (or not having) adequate PA (defined as three or more vigorous sessions/week; or five or more walking or moderate sessions/week; or 1-2 vigorous sessions/week and 3-4 walking or moderate sessions/week according to previous procedures) [39]. Associations between repeat participation and change in diet and PA (calculated 
by subtracting baseline from post-intervention scores for each contest) and percent change in weight during the first participation occasion were further adjusted for gender and age, as these variables have been shown previously to affect contest outcomes [15]. Crossed random effects Poisson models with random effects for person and team were used to account for the clustering of observations and were adjusted for the exposure to the KHC. Crossed random effects were used for all analyses to account for the clustering of observations within person and within team because participants did not uniquely nest within teams but changed teams across contests [40]. For repeat participation analyses only, results are reported as rate ratios (RR) for at least one occasion of repeat participation.

The analysis of the effect of repeat participation on weight percent change between contests was restricted to sequential participation occasions at least 3 months apart (to allow for weight regain following weight loss [22]). $\mathrm{Cu}$ mulative repeat participation was operationalised as a categorical variable ranging from 2 to $6+$ participation occasions to examine non-linear effects; 6-12 cumulative participation occasions were collapsed to form the category $6+$ due to small numbers. Covariates were age, gender, baseline weight at first participation occasion, and weight percent change in the immediately preceding contest. Linear crossed random effects models were used with random effects for person and team. Results are presented as percent change in weight per month for a one unit increase in the independent variable.

All analyses were conducted using Stata 15.1 (College Station, TX, USA).

\section{Results}

Participation patterns

Over the 12 contests comprising the challenge, 4433 individuals participated, yielding a total of 7504 participation occasions. Participant baseline characteristics and participation patterns are shown in Tables 1 and 2, respectively. (An additional file contains further contest and participation characteristics not shown here.) Single-contest participation was the most common pattern, with 2901 (65.4\%) participants. Contest 5 had the highest single-participation participants $(n=384,8.7 \%)$ and contest 8 had the lowest $(n=75,1.7 \%)$. Among those who had participated more than once $(n=1532$, $34.3 \%)$, participating twice $(n=816,18.4 \%)$ was the most common frequency and no individual competed in all 12 contests. The number of days between the official end of one contest to the start of the next contest ranged between 17 and 245 days.

The participation pattern for most repeaters included some consecutive contest participation $(\mathrm{n}=1147,74.9 \%$ of repeaters). The most frequent pattern was competing
Table 1 Participant baseline characteristics

\begin{tabular}{|c|c|c|}
\hline Baseline characteristic & $\begin{array}{l}\text { All participants } \\
\mathrm{n}(\%) \text { or } \\
\text { mean } \pm \mathrm{sd}\end{array}$ & $\begin{array}{l}\text { Repeaters only } \\
\mathrm{n}(\%) \text { or } \\
\text { mean } \pm \text { sd }\end{array}$ \\
\hline Total & $4433(100 \%)$ & $1532(100 \%)$ \\
\hline Gender (male), n= 4417 & $1174(26 \%)$ & $352(23 \%)$ \\
\hline Age (year), $n=4387$ & $38.3 \pm 12.95$ & $38.2 \pm 12.15$ \\
\hline Weight (kg), $n=4403$ & $96.6 \pm 23.52$ & $97.1 \pm 22.62$ \\
\hline Number of fruit serves/day, $n=3819$ & $1.4 \pm 1.17$ & $1.45 \pm 1.16$ \\
\hline $\begin{array}{l}\text { Number of vegetable serves/day, } n= \\
3932\end{array}$ & $2.1 \pm 1.52$ & $2.1 \pm 1.48$ \\
\hline $\begin{array}{l}\text { Number of sessions/week vigorous PA, } \\
n=3515\end{array}$ & $1.8 \pm 2.40$ & $1.9 \pm 2.68$ \\
\hline $\begin{array}{l}\text { Number of sessions walking/week, } \\
n=3524\end{array}$ & $2.3 \pm 2.71$ & $2.2 \pm 2.41$ \\
\hline $\begin{array}{l}\text { Number of sessions/week moderate } \\
\text { PA, } n=3494\end{array}$ & $1.6 \pm 2.19$ & $1.6 \pm 2.04$ \\
\hline
\end{tabular}

Baseline was defined as an individual's first participation occasion. Analysis included data for 4433 participants, of whom 1532 participated more than once, using a complete case approach.

in contest 11 and contest $12(\mathrm{n}=85,10.4 \%$ of two-time participants). Consecutive participation was more frequent ( $n=489,59.9 \%$ of two-time participants) than skipping one or more contests in between. The number of two-time participants decreased with increasing gap

Table 2 Individuals' participation patterns

\begin{tabular}{|c|c|c|c|c|}
\hline $\begin{array}{l}\text { \# times } \\
\text { competed }\end{array}$ & Type of repetition & $\mathrm{n}$ & $\begin{array}{l}\text { Relative } \\
\%\end{array}$ & $\begin{array}{l}\% \\
\text { total }\end{array}$ \\
\hline 1 & $\mathrm{n} / \mathrm{a}$ & 2901 & 100 & 65.4 \\
\hline \multirow[t]{2}{*}{2} & All & 816 & 100 & 18.4 \\
\hline & Consecutive participation & 489 & 59.9 & \\
\hline \multirow[t]{3}{*}{3} & All & 349 & 100 & 7.9 \\
\hline & 3 consecutive participation & 99 & 28.4 & \\
\hline & $\begin{array}{l}\geq 2 \text { consecutive } \\
\text { participation }\end{array}$ & 295 & 84.5 & \\
\hline \multirow[t]{3}{*}{4} & All & 159 & 100 & 3.5 \\
\hline & 4 consecutive participation & 40 & 25.2 & \\
\hline & $\begin{array}{l}\geq 2 \text { consecutive } \\
\text { participation }\end{array}$ & 156 & 98.1 & \\
\hline 5 & All & 88 & 100 & 1.9 \\
\hline 6 & All & 55 & 100 & 1.2 \\
\hline 7 & All & 28 & 100 & 6 \\
\hline 8 & All & 22 & 100 & .5 \\
\hline 9 & All & 7 & 100 & .2 \\
\hline 10 & All & 5 & 100 & .1 \\
\hline 11 & All & 3 & 100 & .1 \\
\hline Total & & 4433 & 100 & 99.8 \\
\hline
\end{tabular}

Within low frequency repeaters, consecutive participation is further described with percentages relative to the sample repeating. Participation percentage does not equal $100 \%$ due to rounding $(n=4433)$. 
Table 3 Rate ratio for repeat participation in the KHC for baseline characteristics (bivariate analyses)

\begin{tabular}{llll}
\hline $\begin{array}{l}\text { Baseline characteristic } \\
\text { (reference unit) }\end{array}$ & Rate ratio (RR) $)^{b}$ & $95 \% \mathrm{Cl}$ \\
\hline Gender (male) & 1.34 & $(1.18,1.52)$ & $(0.95,1.03)$ \\
Age (10 years) & 0.99 & $(0.99,1.01)$ & 0.001 \\
Weight (5 kg) & 1.00 & $(0.96,1.06)$ & 0.538 \\
Number of fruit serves/day (1 serve/day) & 1.01 & $(0.96,1.03)$ & 0.720 \\
Number of vegetable serves/day (1 serve/day) & 0.99 & $(1.00,1.05)$ & 0.793 \\
Number of sessions/week vigorous PA (1 session/week) & 1.02 & $(0.96,1.01)$ & 0.052 \\
Number of sessions/week walking (1 session/week) & 0.99 & $(0.98,1.04)$
\end{tabular}

${ }^{a}$ Baseline defined as participants' first participation occasion. ${ }^{b}$ per 1 reference unit increase or compared to categorical reference unit. As a complete case approach was used, the $\mathrm{n}$ for each analysis varies: gender $=4089$, age $=4063$, weight $=4076$, fruit serves $=3494$, vegetable serves $=3607$, sessions vigorous $P A=$ 3196 , sessions walking $=3202$, and sessions moderate $P A=3175$

between contests, with just 4 persons $(0.5 \%$ of twotime participants) competing in only the first and last contests. Among those competing three or four times, most ( 84.5 and $98.1 \%$, respectively) had at least two consecutive participations and few (25.2 and $28.4 \%$, respectively) had no skipped contest between their first and last participation.

\section{Likelihood of repeating}

Table 3 shows the bivariate rate ratios (with 95\% CI) of repeating at least once for characteristics of participants on their first occasion of participating, adjusting for the number of possible contests they could enter as described in the methods. Among the demographic, weight and behaviour measures only gender and, marginally, amount of vigorous PA showed significant relationships with the likelihood of repeat participation. Female participants had a $34 \%$ higher likelihood of repeating, and the likelihood of repeating increased by $2 \%$ for every extra session of vigorous PA reported at registration in the first participation. Neither the number of fruit nor vegetable serves nor PA behaviour bore much relation to repeat participation. Further, meeting dietary and PA recommendations at first participation start, versus not meeting these, was not related to repeat participation (see additional file, supplemental Table 4).

Table 4 shows the rate ratio for repeating given participants' outcomes in their first contest, adjusted for age and gender and possible repetition occasions. The likelihood of repeat participation increased with increased weight loss and with a higher number of sessions of walking and moderate PA as measured at the end of their first occasion of participation. Specifically, the likelihood of repeating increased by $3 \%$ per percentage of registration weight lost and by 7 and $6 \%$, respectively, for each session increase of walking and moderate PA. There were marginally significant results for number of vegetable serves $(p=0.071)$ and of vigorous PA sessions $(\mathrm{p}=0.065)$, both demonstrating an incremental effect as the number increased.

\section{Impact of repeat participation on weight between contests}

Figure 1 shows participants' raw mean weight at start and end of each contest occasion, for those competing two or more times. It appears that there is a decrease in weight during each contest and a subsequent increase during the time before the subsequent participation.

Table 5 shows weight changes between contests, adjusted for age, gender, percentage weight lost during the previous contest, the starting weight on the first occasion of participating, and the number of participation occasions at that point. Due to small numbers, participation occasions 6-11 were combined. Holding all else equal, for every percentage increase in the amount of weight lost, there was a 0.05 percentage gain per month in between contests. However, for every kilogram heavier the participant was on their first occasion of competing, there was a small (0.002) decrement in the percentage weight regain. There appeared to be somewhat of a dose-response effect for repeat participation whereby the amount of weight gain between contests increased as the number of participation occasions increased. For example, predicted percentage gain per month generated using average values on all other covariates showed that the weight gain per month after two participation occasions was $0.30 \%$, after four was $0.57 \%$, and after six was $0.70 \%$ per month (data not shown). A supplementary analysis using participation as a continuous variable found that the average increase in weight percent per month was $0.10(.06, .13, \mathrm{p}<.001)$ per participation occasion.

\section{Discussion}

This study analysed participation patterns and participant weight change between contests over 7 years 
Table 4 Rate ratio for repeat participation in the KHC for outcomes of participants' first participation occasion

\begin{tabular}{llll}
\hline Change in first participation occasion & Rate ratio (RR) & $95 \% \mathrm{Cl}$ & $\mathrm{p}$-value \\
\hline Weight \% lost (1\%) & 1.03 & $(1.02,1.05)$ & $(0.98,1.09)$ \\
Number of fruit serves/day (1 serve/day) & 1.03 & $(1.00,1.11)$ & 0.237 \\
Number of vegetable serves/day (1 serve/day) & 1.05 & $(1.00,1.08)$ & 0.071 \\
Number of sessions/week vigorous PA (1 session/week) & 1.04 & $(1.03,1.11)$ & 0.065 \\
Number of sessions/week walking (1 session/week) & 1.07 & $(1.02,1.10)$ & $<0.001$ \\
Number of session/week moderate PA (1 session/week) & 1.06 & 0.005
\end{tabular}

a per 1 reference unit increase, and further adjusted for sex and age and accounting for possible repetition occasions. As a complete case approach was used, the $\mathrm{n}$ for each analysis varies: weight $=2397$, fruit serves $=1840$, vegetable serves $=1201$, sessions vigorous $P A=992$, sessions walking $=992$, sessions moderate $\mathrm{PA}=974$

(2012-2018) of a community-based weight loss program for Aboriginal Australians. About one-third of participants repeated the community weight loss program. Gender was a strong predictor of whether someone participated more than once, with behavioural measures contributing minimally to this prediction. Between competitions, repeat participants regained some of the weight they had previously lost, with smaller regain the heavier a participant was when they first joined the KHC.

\section{Participation}

The KHC is a long-running program with increasing appeal [15]. While the most common participation pattern in the $\mathrm{KHC}$ was a single participation occasion, repeaters accounted for about one-third of the participants. In our study, almost no baseline characteristic predicted repeat participation. The observed increased likelihood of repeat participation among women contrasts with results from studies of online PA and other behaviour change programs which found no gender difference $[27,41]$ or a higher likelihood for repeat participation among men [41]. In those studies and this, males comprised a minority of the study population, consistent with findings that men are less likely to seek assistance for weight loss [42]. Reports of age [27, 41] predicting repeat participation contrast with our findings but could be explained by the internet-based program format of those programs. Previous research found attaining sufficient vigorous PA did not determine likelihood of repeat participation [27], whereas here the amount of vigorous PA reported at baseline was marginally $(p=.052)$ related to the likelihood of repeat participation. Again, the different program formats may explain variabilities in health behaviours as participation predictors. Additionally, the KHC serves a unique population (Aboriginal Australians) and its incorporation of their values (e.g., reflecting the strong value in family and community by having participation based on teams) may influence repeat participation likelihood [43]. Investigating participant motives for involvement in the KHC and satisfaction with the program format may elucidate why a gender difference in repeat participation exists and help tailor the program to maximize its reach.

Whilst we identified predictors of repeat participation, we did not measure goals and expectations. We did model the likelihood of repeating on changes in lifestyle outcomes during participants' first participation

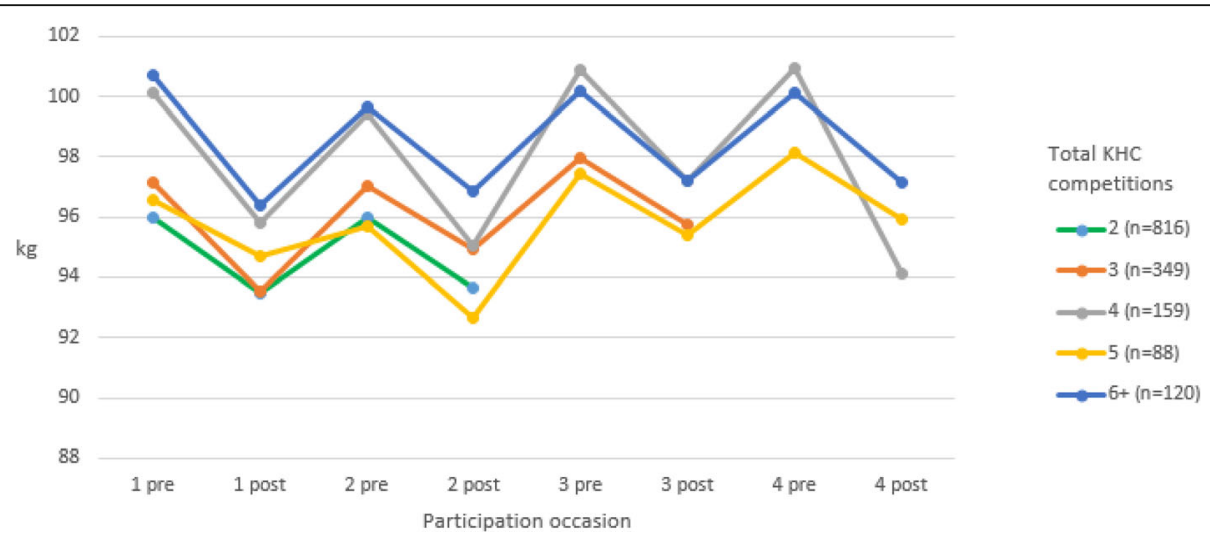

Fig. 1 Weight changes over four participation occasions. Participants' raw mean weight at start and end of each contest occasion, for those competing two or more times, censored at 4 participations; $n=1532$ 
Table 5 Adjusted percentage weight change per month between contests at least three months apart $(n=1107)^{1}$

\begin{tabular}{llll}
\hline $\begin{array}{l}\text { Variable (reference } \\
\text { category) }\end{array}$ & $\begin{array}{l}\text { Average change in } \\
\text { between-contest weight } \\
\text { change (\%) }\end{array}$ & $95 \% \mathrm{Cl}$ & p-value \\
\hline Age in years & -0.001 & -0.005, & 0.475 \\
& 0.03 & 0.002 & \\
Gender (male) & & -0.80, & 0.636 \\
& & 0.13 & \\
Weight, \% change & 0.05 & 0.04, & $<0.001$ \\
during last & & 0.06 & \\
competition & & & \\
Weight, in kg at first & -0.002 & -0.004, & 0.025 \\
repeat occasion & & -0.0002 & \\
Number of & & & $<0.001^{2}$ \\
participation & & & \\
occasions (two) & & & \\
3 occasions & 0.15 & 0.05, & \\
& & 0.25 & \\
4 occasions & 0.27 & 0.11, & \\
& & 0.44 & \\
5 occasions & 0.38 & 0.20, & \\
& & 0.57 & \\
6-11 occasions & 0.39 & 0.20, & \\
& & 0.59 & \\
\hline
\end{tabular}

${ }^{1}$ Missing values were excluded using a complete case approach. Analysis included data for 801 people across 1107 records. ${ }^{2} \mathrm{p}$-value is for joint effect

occasion. Greater increases in walking and moderate PA sessions and greater weight loss were associated with increased likelihood of repeating by between 3 and $7 \%$. Previous research has also found higher levels of participation $[11,25,26]$ are associated with improved weight outcomes. Identifying whether actualized behaviour changes were participant goals could provide insight into the relationships between goals, behaviour changes and repeat participation. Further, there are a variety of other motives for program participation, including health concerns and social support [44], and these directly relate to the secondary goals of the KHC. Motives may differ between first-time and repeat participants in physical activity events [45]. Investigating repeat and non-repeat participant motives may be helpful for further program development or to elucidate other strategies needed to combat weight loss.

\section{Weight change between repeat contests}

Repeat participants gained weight between contests at a rate of $0.05 \%$ body weight per month. Similarly, weight regain, of approximately $3 \%$, was also found during the 40-week length gap between first and second participations in another community-based weight loss competition [11]. That weight is regained between contests, increases with each participation occasion, and correlated with a higher percent weight lost during the program suggests weight cycling may be a problem among repeat participants. Figure 1 also lends itself to such an interpretation. Positively, regain may be less of a problem for heavier participants (here and in the American program [11]), which suggests community-based programs may have a positive health impact among obese individuals. Further, this type of community program may confer additional benefit for weight loss through its team-based format as weight loss can be clustered within teams [12] and team-based participation may increase the amount weight lost [11, 14]. On the other hand, team-based participation may also increase the likelihood for regain as the social support available from teammates during participation disperses [11]. Social support has been implicated as having a potential role in weight loss [14] while individual coping skills, such as self-monitoring [46, 47] and emotional control [48], may be key to maintenance. Thus, structuring a community program to maximize the benefits of social support during competition while teaching individual skills for maintenance may be important to minimize weight cycling. Investigating coping skills of repeaters and non-repeaters may indicate where skill differences exist and may be more valuable for weight maintenance among this population.

Males comprise an equal proportion of the overweight/obese Aboriginal population [49]. They may be less likely to lose weight in the $\mathrm{KHC}$ [35] and have lower participation and probability of repeating than females, but our results indicate they are no more likely than females to regain lost weight. Similarly, the observed gender difference in weight regain disappeared with participation cycles in the American program [11] and a recent systematic review found participant demographics were not associated with weight loss maintenance [22]. Therefore, addressing avenues to increase male participation and weight loss success in the $\mathrm{KHC}$ could have long-term population health benefits.

That weight increases with time between participation occasions reinforces the need for weight maintenance support. Evidence suggests self-monitoring assists with weight maintenance $[46,47]$, so incorporating this as part of the program may mitigate weight regain among participants. Notably, the $2013 \mathrm{KHC}$ contest included a maintenance phase comprising individual (e.g., monthly weigh-ins) and team-based (e.g., team sports carnival competition) components [35]. While few KHC participants were evaluated in the maintenance phase, the results were promising: the mean weight at contest end and 9 months thereafter were comparable [35]. There is some evidence that web-based programs can assist maintenance as well, particularly in the short-term [50], and the $\mathrm{KHC}$ already has a social media presence which could act as a platform for post and/or between 
competition weight loss maintenance support. Weight loss is best maintained with continued support following program end. To this end, the $\mathrm{KHC}$ encourages participants to enrol in a free 6-month telephone coaching service and facilitates enrolment through an opt-in option at contest registration for participant contact details to be shared with the service. Evaluating participant uptake and outcomes through the coaching service would provide a more complete picture of long-term weight loss outcomes of KHC participants.

\section{Strengths and limitations}

This is the first study to explore weight maintenance among repeat participants of an Aboriginal communitybased team weight loss competition. Strengths of this study include the inclusion of 12 contests over 7 years, using a minimum gap of 3 months between participation occasions to allow sufficient time for weight regain, the large sample size, and the inclusion of nutrition and PA behaviours.

Limitations include the ability to measure weight maintenance only among those who repeated the program. The KHC has been shown to be effective for short-term weight loss and healthy lifestyle adaptation [15], and it may be that non-repeaters are able to maintain their weight loss and health behaviours. Among repeaters, we cannot state to what extent the subsequent participation might have mitigated an otherwise larger increase in weight.

\section{Conclusion}

The KHC has been successful in attracting increasingly large numbers of participants, starting with 324 in its first year and increasing to 4433 individuals having participated over the first 7 years of operation. Many participants return to the competition repeatedly, especially women, who had a $34 \%$ higher likelihood of repeat than men. Both program weight loss and increases in number of sessions of walking and moderate PA were associated with small (3-7\%) but significant increases in likelihood of repeat participation. However, the association between contest weight reduction and subsequent regain $(0.05 \%$ regain per month for every $1 \%$ body weight reduced) might signal a need for the program to incorporate weight loss maintenance strategies to better conserve the benefits accrued during competition. Tracking the longer-term outcomes of those not returning to the competition would assist in understanding the full impact of the KHC. Further, qualitative research with those who do and do not repeat would yield insights into people's patterns of engagement with the program.

\section{Supplementary information}

Supplementary information accompanies this paper at https://doi.org/10. 1186/s12889-020-09086-6.

\section{Additional file 1.}

Weight_change_among_repeat_Additional_file_1.docx. The additional file contains contest and participation data in tabular form: contest dates (including number of days between each contest), most frequent participation patterns, non-repeater participant characteristics, and further rate ratios for repeat participation.

\section{Abbreviations}

PA: Physical activity; KHC: NSW Aboriginal Knockout Health Challenge; NSW: New South Wales; kg: Kilogram; sd: Standard deviation; Cl: Confidence interval; RR: Rate ratio

\section{Acknowledgements}

The authors would like to acknowledge the NSW Aboriginal Knockout Health Challenge Advisory Committee and their continuing support to improve health in NSW Aboriginal communities through the implementation of the NSW KHC, as well as their support for this project. The authors further wish to acknowledge the Traditional Owners of this Land.

\section{Authors' contributions}

$E B G, A C G$ and $A B$ conceived and designed this work; ACG, AC, RF and KR were instrumental in data acquisition; LS designed the analysis approach, ACG analysed data and both interpreted the data; EBG and ACG drafted the work, with $A C, A M$ and $A B$ contributing to its revision. All authors read and approved the final manuscript.

\section{Funding}

This research was funded by The Australian Prevention Partnership Centre. The funding body had no role in the design of the study and collection, analysis, and interpretation of data nor in writing the manuscript.

\section{Availability of data and materials}

The datasets generated and/or analysed during the current study are not publicly available due to the conditions of ethics approval. The contest data that support the findings of this study are not publicly available and restrictions apply to their availability; data may be made available from NSW Ministry of Health, or from the authors upon reasonable request and with permission of NSW Ministry of Health.

\section{Ethics approval and consent to participate}

Ethics approval for the secondary analysis was provided by the Aboriginal Health and Medical Research Council (Project 1125/15) and the University of Sydney (2019/425).

\section{Consent for publication}

N/A

\section{Competing interests}

The authors declare a non-financial competing interest for authors Fonua, Milat and Reid who work for the organisation which operates the NSW Aboriginal Knockout Health Challenge.

\section{Author details}

${ }^{1}$ The Australian Prevention Partnership Centre, Sydney, New South Wales, Australia. ${ }^{2}$ The University of Sydney, Sydney School of Public Health, Camperdown, New South Wales, Australia. ${ }^{3}$ Centre for Epidemiology and Evidence, NSW Ministry of Health, St Leonards, New South Wales, Australia. ${ }^{4}$ School of Public Health and Community Medicine, University of NSW, Kensington, New South Wales, Australia. ${ }^{5}$ NSW Office of Preventive Health, St Leonards, New South Wales, Australia. 
Received: 1 March 2020 Accepted: 10 June 2020

Published online: 26 June 2020

\section{References}

1. Canuto KJ, Spagnoletti B, McDermott RA, Cargo M. Factors influencing attendance in a structured physical activity program for Aboriginal and Torres Strait islander women in an urban setting: a mixed methods process evaluation. Int J Equity Health. 2013;12:11.

2. Davey M, Moore W, Walters J. Tasmanian aborigines step up to health: evaluation of a cardiopulmonary rehabilitation and secondary prevention program. BMC Health Serv Res. 201337(1):79-82.

3. Dimer L, Dowling T, Jones J, Cheetham C, Thomas T, Smith J, McManus A, Maiorana A. Build it and they will come: outcomes from a successful cardiac rehabilitation program at an Aboriginal medical service. Aust Health Rev. 2013:37:79-82

4. Mendham AE, Duffield R, Marino F, Coutts AJ. A 12-week sports-based exercise programme for inactive indigenous Australian men improved clinical risk factors associated with type 2 diabetes mellitus. J Sci Med Sport. 2015;18(4):438-43.

5. O'Dea K. Marked improvement in carbohydrate and lipid metabolism in diabetic Australian aborigines after temporary reversion to traditional lifestyle. Diabetes. 1984:33(6):596-603.

6. Australian Institute of Health and Welfare: The health and welfare of Australia's Aboriginal and Torres Strait Islander peoples. In., vol. Cat. no. IHW 147. Canberra: AlHW; 2015

7. Standing Committee on Aboriginal and Torres Strait Islander Affairs. In: Ho R, editor. Sport - More Than Just a Game. Canberra: The Parliament of the Commonwealth of Australia; 2013.

8. Browne-Yung K, Ziersch A, Baum F, Gallaher G. Aboriginal Australians' experience of social capital and its relevance to health and wellbeing in urban settings. Soc Sci Med. 2013;97:20-8.

9. Stronach M, Maxwell H, Taylor T. 'Sistas' and aunties: sport, physical activity, and indigenous Australian women. Ann Leis Res. 2016;19(1):7-26.

10. Primack C. A review and critique of published real-world weight management program studies. Postgrad Med. 2018;130(6):548-60.

11. Funk MD, Lee M, Vidoni ML, Reininger BM. Weight loss and weight gain among participants in a community-based weight loss Challenge. BMC Obes. 2019;6:2

12. Leahey TM, Kumar R, Weinberg BM, Wing RR. Teammates and social influence affect weight loss outcomes in a team-based weight loss competition. Obesity. 2012;20(7):1413-8.

13. Shirinzadeh M, Afshin-Pour B, Angeles R, Gaber J, Agarwal G. The effect of community-based programs on diabetes prevention in low- and middle-income countries: A systematic review and meta-analysis. Glob Health. 2019:15(1):10.

14. Wing RR, Pinto AM, Crane MM, Kumar R, Weinberg BM, Gorin AA. A statewide intervention reduces BMI in adults: shape up Rhode Island results. Obesity. 2009;17(5):991-5.

15. Grunseit AC, Bohn-Goldbaum E, Crane M, Milat A, Cashmore A, Fonua R, Gow A, Havrlant R, Reid K, Hennessey K, et al. Participant profile and impacts of an Aboriginal healthy lifestyle and weight loss challenge over four years 2012-2015. Aust N Z J Public Health. 2019;43(4):328-33.

16. Ryan DH, Yockey SR. Weight loss and improvement in comorbidity: differences at 5, 10, 15\%, and over. Curr Obes Rep. 2017:6(2):187-94.

17. El Ghoch M, Calugi S, Dalle Grave R. Weight cycling in adults with severe obesity: a longitudinal study. Nutr Diet. 2018;75(3):256-62.

18. Welti LM, Beavers DP, Caan BJ, Sangi-Haghpeykar H, Vitolins MZ, Beavers KM. Weight fluctuation and cancer risk in postmenopausal women: the women's health initiative. Cancer Epidemiol Biomarkers Prev. 2017;26(5): 779-86.

19. Wing RR, Espeland MA, Clark JM, Hazuda HP, Knowler WC, Pownall HJ, Unick J, Wadden T, Wagenknecht L. Association of weight loss maintenance and weight regain on 4-year changes in CVD risk factors: the action for health in diabetes (look AHEAD) clinical trial. Diabetes Care. 2016;39(8):1345-55.

20. Berger SE, Huggins GS, McCaffery JM, Jacques PF, Lichtenstein AH. Change in Cardiometabolic risk factors associated with magnitude of weight regain 3 years after a 1-year intensive lifestyle intervention in type 2 diabetes mellitus: the look AHEAD trial. J Am Heart Assoc. 2019;8(20):e010951.

21. Dombrowski SU, Knittle K, Avenell A, Araújo-Soares V, Sniehotta FF. Long term maintenance of weight loss with non-surgical interventions in obese adults: systematic review and meta-analyses of randomised controlled trials. BMJ (Online). 2014;348
22. Varkevisser RDM, van Stralen MM, Kroeze W, Ket JCF, Steenhuis IHM Determinants of weight loss maintenance: a systematic review. Obes Rev. 2019;20(2):171-211.

23. Stubbs RJ, Morris L, Pallister C, Horgan G, Lavin JH. Weight outcomes audit in 1.3 million adults during their first 3 months' attendance in a commercial weight management programme. BMC Public Health. 2015;15:882.

24. Venditti EM, Bray GA, Carrion-Petersen ML, Delahanty LM, Edelstein SL, Hamman RF, Hoskin MA, Knowler WC, Ma Y. First versus repeat treatment with a lifestyle intervention program: attendance and weight loss outcomes. Int J Obes. 2008;32(10):1537-44.

25. Dandanell S, Ritz C, Verdich E, Dela F, Helge JW. Repeated lifestyle interventions lead to progressive weight loss: a retrospective review chart study. Scand J Public Health. 2017:45(3):305-13.

26. Mitchell NS, Dickinson LM, Kempe A, Tsai AG. Determining the effectiveness of take off pounds sensibly (TOPS), a nationally available nonprofit weight loss program. Obesity. 2011;19(3):568-73.

27. Verheijden MW, Jans MP, Hildebrandt VH, Hopman-Rock M. Rates and determinants of repeated participation in a web-based behavior change program for healthy body weight and healthy lifestyle. J Med Internet Res. 2007;9(1).

28. Lahti-Koski M, Männistö S, Pietinen P, Vartiainen E. Prevalence of weight cycling and its relation to health indicators in Finland. Obes Res. 2005;13(2): 333-41.

29. Madigan CD, Pavey T, Daley AJ, Jolly K, Brown WJ. Is weight cycling associated with adverse health outcomes? A cohort study. Prev Med. 2018; 108:47-52.

30. Pacanowski CR, Linde JA, Faulconbridge LF, Coday M, Safford MM, Chen $H$, Yanovski SZ, Ewing L, Wing R, Jeffery RW. Psychological status and weight variability over eight years: results from look AHEAD. Health Psychol. 2018; 37(3):238-46.

31. Rhee EJ, Cho JH, Kwon H, Park SE, Park CY, Oh KW, Park SW, Lee WY. Increased risk of diabetes development in individuals with weight cycling over 4 years: the Kangbuk Samsung health study. Diabetes Res Clin Pract. 2018;139:230-8

32. Zwaan M, Engeli S, Müller A. Temperamental factors in severe weight cycling. A cross-sectional study. Appetite. 2015;91:336-42.

33. Mitchell NS, Prochazka AV, Glasgow RE. Time to RE-AIM: Why community weight loss programs should be included in academic obesity research. Prev Chronic Dis. 2015;91:336-42

34. Worick A, Petersons M. Weight loss contests at the worksite: results of repeat participation. J Am Diet Assoc. 1993;93(6):680-1.

35. Passmore E, Shepherd B, Milat A, Maher L, Hennessey K, Havrlant R, Maxwell M, Hodge W, Christian F, Richards J, et al. The impact of a community-led program promoting weight loss and healthy living in Aboriginal communities: the New South Wales knockout health challenge. BMC Public Health. 2017;17(1):951

36. Dal Grande E, Fullerton S, Taylor AW. Reliability of self-reported health risk factors and chronic conditions questions collected using the telephone in South Australia, Australia. BMC Med Res Methodol. 2012;12(1):108-17.

37. Petrie A, Sabin C. Medical statistics at a glance. Hoboken: Wiley \& Sons; 2019.

38. National Health and Medical Research Council. Eat for Health: Australian Dietary Guidelines. Canberra: NHMRC; 2013.

39. Smith BJ, Marshall AL, Huang N. Screening for physical activity in family practice: evaluation of two brief assessment tools. Am J Prev Med. 2005 26(4):256-64.

40. StataCorp. STATA Multilevel Mixed Effects Reference Manual. Release 13 College Station, TX: Stata Press; 2013.

41. Wanner M, Martin-Diener E, Bauer G, Braun-Fahrlander C, Martin BW. Comparison of trial participants and open access users of a Web-based physical activity intervention regarding adherence, attrition, and repeated participation. J Med Internet Res. 2010;12(1):e3.

42. Bunt SNW, Mérelle SYM, Steenhuis IHM, Kroeze W. Predictors of need for help with weight loss among overweight and obese men and women in the Netherlands: A cross-sectional study. BMC Health Serv Res. 2017:17(1):819.

43. Parmenter J, Basit T, Nelson A, Crawford E, Kitter B. Chronic disease selfmanagement programs for Aboriginal and Torres Strait islander people: factors influencing participation in an urban setting. Health Promot J Aust. 2020;31(1): 104-11.

44. Hill B, Christine Green B. Repeat participation as a function of program attractiveness, socializing opportunities, loyalty and the sportscape across three sport facility contexts. Sport Manage Rev. 2012;15(4):485-99. 
45. Snelgrove R, Wood L. Attracting and leveraging visitors at a charity cycling event. J Sport Tourism. 2010;15(4):269-85.

46. Ross KM, Qiu P, You L, Wing RR: Week-to-Week Predictors of Weight Loss and Regain. Health Psychology; 2019 Dec;38(12):1150-8.

47. Wing RR, Crane MM, Thomas JG, Kumar R, Weinberg B. Improving weight loss outcomes of community interventions by incorporating behavioral strategies. Am J Public Health. 2010;100(12):2513-9.

48. Eykelenboom M, van Stralen MM, Poelman MP, IHM S. Patterns of weight loss and their determinants in a sample of adults with overweight and obesity intending to lose weight. Nutr Diet. 2018.

49. Australian Bureau of Statistics. Australian Aboriginal and Torres Strait Islander Health Survey: Updated Results, 2012-13. Canberra: Australian Bureau of Statistics; 2014

50. Holmes WS, Moorhead SA, Coates VE, Bond RR, Zheng H. Impact of digital technologies for communicating messages on weight loss maintenance: a systematic literature review. Eur J Pub Health. 2019;29(2):320-8.

\section{Publisher's Note}

Springer Nature remains neutral with regard to jurisdictional claims in published maps and institutional affiliations.

Ready to submit your research? Choose BMC and benefit from:

- fast, convenient online submission

- thorough peer review by experienced researchers in your field

- rapid publication on acceptance

- support for research data, including large and complex data types

- gold Open Access which fosters wider collaboration and increased citations

- maximum visibility for your research: over $100 \mathrm{M}$ website views per year

At BMC, research is always in progress.

Learn more biomedcentral.com/submissions 